\section{High HIV prevalence and associated factors in a remote community in the Rwenzori region of Western Uganda}

\author{
John Rubaihayo, ' Surat Akib, ${ }^{2}$ \\ Ezekiel Mughusu, ${ }^{3}$ Andrew Abaasa ${ }^{4}$ \\ 'Public Health Department, Mountains \\ of the Moon University, Fort Portal; \\ ${ }^{2}$ School of Health Sciences, Kampala \\ International University, Western \\ Campus;
}

${ }^{3}$ Medical Department, Kabarole District

Local Government;

${ }^{4}$ Medical Research Council (MRC)/

Uganda Virus Research Institute (UVRI)

Research Unit on AIDS, Entebbe, Uganda

\section{Abstract}

In Uganda, previous studies have shown a tremendous decline in HIV prevalence over the past two decades due to changes in sexual behavior with a greater awareness of the risks involved. However, studies in Fort-Portal municipality, a rural town in Western Uganda, continued to show a persistent high HIV prevalence despite the various interventions in place. We conducted a study to establish the current magnitude of HIV prevalence and the factors associated with HIV prevalence in this community. This cross-sectional study was conducted between July and November 2008 . Participants were residents of Fort-Portal municipality aged 15-49 years. A populationbased HIV sero-survey and a clinical review of prevention of mother to child HIV transmission (PMTCT) and voluntary counseling and HIV Testing (VCT) records were used to collect quantitative data. An inteviewer administered structured questionnaire was used to collect qualitative data on social deographics, risk behaviour and community perceptions. Focus group discussions (FGDs) and in-depth interviews provided supplementary data on community perceptions. Logistic regression was used in the analysis. The overall HIV prevalence in the general population was $16.1 \%$ [95\% CI; 12.5-20.6]. Prevalence was lower among women (14.5\%; 95\% CI; 10.0-19.7) but not significantly different from that among men (18.7\%; 95\% CI; 12.5-26.3) $\left(\chi^{2}=0.76, \mathrm{P}=0.38\right)$. Having more than 2 sexual partners increased the odds of HIV by almost 2.5 times. None or low education and age over 35 years were independently associated with HIV prevalence $(\mathrm{P}<0.05)$. Most participants attributed the high HIV prevalence to promiscuity/multiple sexual partners (32.5\%), followed by prostitu- tion (13.6\%), alcoholism (10.1\%), carelessness $(10.1 \%)$, poverty $(9.7 \%)$, ignorance $(9.5 \%))$, rape $(4.7 \%)$, drug abuse $(3.6 \%)$ and others (malice/malevolence, laziness, etc.) (6.2\%). Although there was a slight decline compared to previous reports, the results from this study confirm that HIV prevalence is still high in this community. In order to prevent new infections, the factors mentioned above need to be addressed, and we recommend that education aimed at changing individual behavior should be intensified in this community.

\section{Introduction}

Several studies in sub-Saharan Africa have reported divergent trends of the HIV epidemic with some countries experiencing declining or stabilizing epidemic while a few others still record an increasing epidemic. ${ }^{1-21}$ Variability in HIV prelavence has also been observed in subpopulations in different countries with generalized HIV epidemics in sub-Saharan Africa. ${ }^{1,2,59}$ Uganda is among the African countries with generalized HIV epidemics that have registered a significant decline in the overall prevalence of HIV/AIDS in the last two decades. ${ }^{1,9,10}$ Although there is new evidence of an increase in HIV infections in some parts of Uganda, ${ }^{12}$ several other studies in both urban and rural areas have shown a tremendous decline in HIV prevalence associated with increased awareness and significant decrease in sexual behavior at risk. ${ }^{12-22}$ The Uganda National sero and behavioural survey $2004 / 5^{10}$ showed adult HIV prevalence declined from $18-30 \%$ in the early 1990 s to $6.4 \%$ in 2005 . The report further showed an estimated 1.1 million Ugandans living with the HIV/AIDS in 2005 with lowest prevalence in the West Nile region (2.3\%) and highest prevalence in Central region (8.5\%), followed by North ern region (8.2\%), Western region (6.9\%) and Eastern region (5.3\%).

According to the 2003 sexually transmitted diseases (STDs)/AIDS surveillance report by the Uganda Ministry of Health, ${ }^{23}$ the most predominant factors driving the HIV epidemic in most communities in Uganda were sexual behavior at risk (multiple sexual partners, extra-marital sex, early age sex, unprotected casual sex), infection with sexually transmitted infections (STIs) such as syphilis and herpes simplex virus type 2 (HSV-2), and sociocultural and economic factors (poverty, alcoholism, prostitution, drug abuse, lack of male circumcision, domestic violence, conflict and civil strife). Since HIV infection in Uganda is mainly sexually transmitted, ${ }^{10}$ promotion of safer sexual behavior, particularly sexual abstinence, mutual faithfulness and condom use (the "ABC" approach), has been the main HIV/AIDS prevention strategy throughout the
Correspondence: John Rubaihayo, Public Health Department, Mountains of the Moon University, P.0. Box 837, Fort-Portal, Uganda.

E-mail: rubaihayoj@yahoo.co.uk

Key words: HIV, epidemiology, infectious diseases.

Contributions: JR developed the study design, participated in data collection, analysis and manuscript writing; AS participated in study design and manuscript writing; EM participated in data collection, laboratory work and manuscript writing; AA participated in study design, data analysis and manuscript writing.

Acknowledgments: we acknowledge the study participants who volunteered to give samples and relevant information unreservedly. We also acknowledge the contribution of the local leaders of the six parishes of Fort-Portal municipality (i.e. Kitumba, Njara, Kagote, Rwengoma, Kasusu and Bazaar) without whom access to the study participants would have been difficult. We extend our sincere appreciation to Mountains of the Moon University for the financial support and Dr. Okech Joa Ojony, the District Health officer Kabarole for the HIV test kits and the Medical Superintendents of Fort-Portal regional referral hospital, Kabarole hospital and Virika hospital for their support.

Conflict of interest: the authors report no conflicts of interest.

Received for publication: 19 December 2009. Revision received: 7 September 2010.

Accepted for publication: 8 September 2010.

This work is licensed under a Creative Commons Attribution 3.0 License (by-nc 3.0).

CC Copyright J. Rubaihayo et al., 2010 Licensee PAGEPress, Italy

Infectious Disease Reports 2010; 2:e13 doi:10.4081/idr.2010.e13

country. To monitor HIV incidence and prevalence trends, four surveillance systems have been used in Uganda: longitudinal cohort studies describing the trends in HIV incidence, antenatal care (ANC)/prevention of mother to child HIV transmission (PMTCT) sentinel surveillance, voluntary HIV counseling and testing (VCT) sentinel surveillance and populationbased HIV-sero surveys which describe trends in HIV prevalence. ${ }^{24}$

Population based sero-surveys are the most preferred means for monitoring HIV prevalence because data are systematically collected and are more representative than in ANC/PMTCT and VCT-based sero-surveillance. ${ }^{25-26}$ However, they are expensive and are usually conducted after long intervals. ${ }^{25}$ ANC sentinel HIV surveillance system based on annual antenatal HIV serological surveys in selected sentinel clinics was established in 
Uganda in $1989 .{ }^{23}$ Later, the Uganda Ministry of Health adopted the policy on PMTCT following evidence in 1999 that single dose nevirapine can significantly lower mother to child HIV transmission. ${ }^{14}$ Since then, the Ministry of Health has implemented a nation-wide PMTCT program integrated with ANC services in selected sentinel HIV surveillance sites spread throughout the country. However, since PMTCT is ANC-based, the program does not collect any information on HIV prevalence in men, non-pregnant women, nor women who either do not attend clinics for pregnancy care or who receive ANC at facilities not represented in the PMTCT program. ${ }^{27}$ VCT programs were developed to address gaps in the PMTCT program and have expanded rapidly in recent years as a complementary data source for monitoring the trend of the HIV epidemic in many sub-Saharan African countries. ${ }^{28-29}$ In Uganda, the Ministry of Health developed the first VCT policy in 2002. ${ }^{29}$ This was later revised in 2005 to include home-based HIV testing and counseling (HBHCT) and routine counseling and testing (RCT) that involves provider initiated HIV testing and counseling. ${ }^{10-11}$ Since then, VCT/RCT services have been launched in all major hospitals (national, regional and district level) and health centers (at county level) to offer HIV counseling and testing, antiretroviral treatment, and home-based care and support to persons living with HIV/AIDS in Uganda.

Fort-Portal municipality is a remote town located in the Ruwenzori region in the foothills of the Rwenzori mountains, $290 \mathrm{~km}$ west of Kampala (capital of the Republic of Uganda) and about $70 \mathrm{~km}$ from the boarder with the Democratic Republic of Congo (DRC). The town was hit by the HIV epidemic as early as the 1980s and was one of the most severely affected areas in Uganda. ${ }^{30}$ It has an estimated population of $49,873^{31}$ dominated by the Batooro ethnic community, and is a hub of business in this most agriculturally productive region of Uganda. Administratively, the town is divided into three divisions (East, West and South) with three major hospitals, one of which is a regional referral hospital (FortPortal hospital) and the other two are private hospitals (Virika and Kabarole hospitals). VCT and PMTCT services were introduced by the government at the three major hospitals around 2004 through private and public sector partnership. Despite the above HIV interventions, previous studies in the municipality showed a relatively high HIV prevalence (1925.4\%) compared to other areas in Uganda. ${ }^{1022}$ A population-based HIV sero-survey and a review of ANC HIV sero-surveillance data (1995) in Fort-Portal municipality ${ }^{30}$ showed that HIV prevalence increased from 19.9-31.7\% between 1991 to 1993 and thereafter declined to $21.7 \%$ among women aged $20-24$ years. Another review of ANC data in $2006^{32}$ found an overall prevalence of $22.1 \%$ for the period 1991 94 and 19.0\% for the period 1995-2004 among women of reproductive age (15-49 years). Another study that reviewed VCT data at the three major hospitals in $2007^{33}$ reported an HIV prevalence of $25.4 \%$. In addition, the 2004/5 National HIV sero-survey report indicated that the Batooro ethnic community (the predominant tribe in Fort Portal municipality) had the highest HIV prevalence in Uganda at $14.8 \% .^{10}$ However, the factors responsible for this high HIV prevalence in this remote community were not well known. We, therefore, conducted a study: i) to establish the current HIV seroprevalence in the general population and at PMTCT and VCT centers in the municipality; ii) to determine the factors associated with HIV prevalence in the community.

\section{Materials and Methods}

\section{Study design and settings}

The study was cross-sectional involving both quantitative and qualitative data collection methods. A population-based HIV serological survey and a clinical review of PMTCT and VCT records were used to collect quantitative data. Participants were also interviewed using an interviewer administered structured questionnaire on socio-demographics, sexual behavior and community perceptions with regard to HIV prevalence in the municipality. Focus group discussions (FGDs) and in-depth interviews of key informants were used to collect supplementary data on community perceptions. The study was conducted between July and November 2008. The inclusion criteria were: permanent residency in Fort-Portal municipality, age 15-49 years. We defined a permanent resident as an individual who had lived continuously in Fort-Portal municipality for at least two years.

\section{Sample size estimation and sampling}

The required sample size for the populationbased serological survey was estimated by using Epi Info version 3.5.1 Stat Calc software (CDC, Atlanta, GA, USA) for population surveys/ descriptive studies. ${ }^{34}$ We assumed a $5 \%$ sampling error and HIV prevalence of $25.4 \%$ (from the previous study) in a population of 49,873 individuals (based on the Uganda 2002 national population and housing census). ${ }^{33}$ This gave a sample size of 289 . We anticipated a $75 \%$ response rate and therefore adjusted the sample size to 360 to cater for non-responders..$^{35}$

To select the required sample, we used a three-stage cluster random sampling technique. First, six parishes were randomly selected from nine parishes in the three divisions of the municipality with each division being represented by two parishes. Secondly, from each parish, three villages/wards were randomly selected and finally, from each village/ward, 20 households were randomly selected. Any member of the household who met the inclusion criteria and gave their consent was considered in the study. If more than one or all the members of a household were interested, then simple random sampling was applied to select only one person per household. If no household member was present or willing to participate, the household was replaced by the next one.

\section{Household survey}

During the population survey, participants were sensitized about the purpose of the study and requested to provide informed consent. Consenting participants were interviewed using an interviewer administered structured questionnaire on socio-demographics, sexual behavior and perceived risk factors. The interviews and HIV tests were conducted on weekends (Sundays) to increase the chance of obtaining a representative sample, since most people in this community are Christians and therefore don't work on Sundays. Prior to individual interviews, focus group discussions and in-depth interviews of key informants were conducted to help gain some insights on community perceptions with regard to factors associated with HIV prevalence in the area. Five focus group discussions were conducted. These included a youth group made up of 5 girls and 4 boys aged between 14-24 years, a group of 11 business women aged between 23 47 years, a group of 8 business men aged between 19-42, an HIV positive living group of 5 men aged 27-49, and another HIV positive living group of 7 women aged 24-49 years. Key informants included local leaders, community health workers and prominent personalities in the community. These were purposively selected for their willingness to participate and for their knowledge and experience of the people of Fort-Portal municipality.

\section{HIV serological tests}

After household interviews, study participants were counseled for HIV testing and consenting participants were offered an HIV test. Blood samples were collected using EDTA vacutainers which were carried to the laboratory and processed on the same day. HIV testing was performed using 3 different rapid tests: Determine HIV1/2 (Abbott Laboratories, Abbott Park, IL, USA), HIV-1/2 Stat-Pak dipstick (Chembio Diagnostic Systems, New York, USA) and Unigold (Trinity Biotech PLC, Bray, Ireland). Positive samples from the Determine test were subjected to a second test using HIV1/2 Stat-Pak Dipstick for confirmation. Samples which were positive on both tests were regarded as sero positive and those with 
negative results on both tests as sero negative. Samples with discordant results on the two tests were re-tested using Unigold as a tiebreaker. Test results from Unigold were taken as conclusive. For quality control, $10 \%$ of the tested samples were taken to the National Laboratory for Reference and Quality Assurance at the Uganda virus research Institute (UVRI) Entebbe, for confirmation before disclosure.

\section{Antenatal care/prevention of mother to child HIV transmission and voluntary HIV counseling and testing records review}

All the three hospitals (i.e. Fort-Portal referral hospital, Virika hospital and Kabarole hospital) were purposively selected for medical records review. PMTCT and VCT clients' data for the period July 2007-June 2008 were extracted from clients' registers on case report forms, entered in a Microsoft access database, and analyzed using STATA version 9.0 (College Park, TX, USA) software.

\section{Ethical considerations and approval}

Ethical clearance was sought from Kampala International University Research and Ethics Committee (IREC) and the study was approved by the National Council for Science and Technology (NCST). Written permission was also obtained from Kabarole Local Government Directorate of Health Services.
Prior to the study, study participants were sensitized about the purpose of the study, counseled on HIV testing and thereafter requested to give informed consent. Participants, who expressed interest in their HIV test results were given the results in private by an HIV counselor after post-test counseling. Those found HIV positive were referred to the ART clinics in the municipality for care or treatment. To ensure confidentiality, VCT and PMTCT patients' medical data were delinked from any personal identifiers (name of the patient) and only anonymous medical data were used in the study.

\section{Data analysis}

Population-based data were entered into Epi Info version 3.1.5 soft ware (CDC, Atlanta, GA, USA), and cleaned and analyzed using STATA version 9.0 (College Park, TX, USA). Data from FGDs and in-depth interviews were transcribed and translated from the local language into English and thereafter a transcript was prepared from which key themes were identified. The themes were used to define the different categories in the structured questionnaire.

Overall and specific HIV prevalence were calculated using descriptive statistics through frequencies and cross tabulations. The $\chi^{2}$ test was used to test for the significance of the differences in the HIV prevalence by demographic characteristics. The strength of association between HIV prevalence and the various associated factors was by both univariable and multivariable logistic regression models. Odds ratios and their $95 \%$ confidence intervals (95\% CI) were used to assess the association between a factor and HIV prevalence. Only factors that were significantly associated with HIV prevalence at univariable analysis $(\mathrm{P}<0.05)$ were included in a multivariable logistic regression model. Tribe was included because it gave a borderline significance $(\mathrm{P}=0.07)$. Sex was included in the multivariable model because it is a known a priori confounder. The role of a factor was assessed by comparing a model without the variable to a full model using the likelihood ratio test. Continuous variables were further tested for a possible linear effect by comparing a model with a continuous variable when the variable was categorized using a likelihood ratio test.

\section{Results}

\section{Population-based behavioral, socio-cultural and HIV sero-survey}

In the population-based sero-survey, a total of 360 participants were interviewed and out of these, 341 (94.7\%) accepted to be tested for HIV of which 207 (60.7\%) were women and 134 (39.3\%) men. Most participants belonged to the Batooro tribe $(82.4 \%), 44.6 \%$ were under

Table 1. Unadjusted and adjusted factors associated with HIV prevalence in Fort-Portal municipality.

\begin{tabular}{|c|c|c|c|c|c|c|c|}
\hline Variables & Category & $\begin{array}{l}\text { HIV }^{+} \\
\text {n }(\%)\end{array}$ & $\begin{array}{l}\text { HIV }^{-} \\
\text {n (\%) }\end{array}$ & $\begin{array}{l}\text { Unadjusted } \\
\text { OR(95\% CI } *\end{array}$ & $\mathbf{P}$ & $\begin{array}{l}\text { Adjusted } \\
\text { OR(95\% CI) }\end{array}$ & $\mathbf{P}$ \\
\hline Sex & $\begin{array}{l}\text { Female } \\
\text { Male }\end{array}$ & $\begin{array}{l}30(14.5) \\
25(18.7)\end{array}$ & $\begin{array}{l}177(85.5) \\
109(81.3)\end{array}$ & $\begin{array}{l}1 \\
1.35(0.76-2.42)\end{array}$ & 0.308 & $\begin{array}{l}1 \\
1.07(0.55-2.05)\end{array}$ & 0.845 \\
\hline Age & $\begin{array}{l}15-24 \\
25-34 \\
35+\end{array}$ & $\begin{array}{l}14(9.2) \\
27(20.9) \\
14(23.3)\end{array}$ & $\begin{array}{r}138(90.8) \\
102(79.1) \\
46(76.7)\end{array}$ & $\begin{array}{l}1 \\
2.61(1.30-5.22) \\
3.00(1.33-6.76)\end{array}$ & $\begin{array}{l}0.007 \\
0.008\end{array}$ & $\begin{array}{l}1 \\
2.13(1.04-4.38) \\
2.62(1.13-6.05)\end{array}$ & $\begin{array}{l}0.039 \\
0.025\end{array}$ \\
\hline Marital status & $\begin{array}{l}\text { Married } \\
\text { Never married } \\
\text { Cohabiting } \\
\text { Divorced/widowed }\end{array}$ & $\begin{array}{r}28(14.3) \\
6(15.4) \\
15(17.6) \\
6(28.6)\end{array}$ & $\begin{array}{r}168(85.7) \\
33(84.6) \\
70(82.4) \\
15(71.4)\end{array}$ & $\begin{array}{l}1 \\
1.09(0.42-2.84) \\
1.29(0.65-2.55) \\
2.40(0.86-6.71)\end{array}$ & $\begin{array}{l}0.859 \\
0.473 \\
0.095\end{array}$ & & \\
\hline Tribe & $\begin{array}{l}\text { Others } \\
\text { Batooro }\end{array}$ & $\begin{array}{c}5(8.3) \\
50(17.8)\end{array}$ & $\begin{array}{r}55(91.7) \\
231(82.2)\end{array}$ & $\begin{array}{l}1 \\
2.38(0.91-6.25)\end{array}$ & 0.078 & $\begin{array}{l}1 \\
2.38(0.89-6.41)\end{array}$ & 0.084 \\
\hline Religion & $\begin{array}{l}\text { Catholic } \\
\text { Protestant } \\
\text { Moslem } \\
\text { Others }\end{array}$ & $\begin{array}{c}23(15.0) \\
23(21.9) \\
3(7.3) \\
6(14.3)\end{array}$ & $\begin{array}{r}130(85.0) \\
82(78.1) \\
38(92.7) \\
36(85.7)\end{array}$ & $\begin{array}{l}1 \\
1.59(0.84-3.01) \\
0.45(0.13-1.57) \\
0.94(0.36-2.49)\end{array}$ & $\begin{array}{l}0.159 \\
0.208 \\
0.942\end{array}$ & & \\
\hline Education & $\begin{array}{l}\text { None } \\
\text { Primary } \\
\text { Secondary } \\
\text { Tertiary }\end{array}$ & $\begin{array}{c}10(34.5) \\
32(17.7) \\
12(11.3) \\
1(4.0)\end{array}$ & $\begin{array}{r}19(65.5) \\
149(82.3) \\
94(88.7) \\
24(96.0)\end{array}$ & $\begin{array}{l}1.00 \\
0.41(0.17-0.96) \\
0.24(0.09-0.64) \\
0.08(0.01-0.68)\end{array}$ & $\begin{array}{l}0.040 \\
0.004 \\
0.020\end{array}$ & $\begin{array}{l}0.41(0.17-0.96) \\
0.24(0.09-0.64) \\
0.08(0.01-0.68)\end{array}$ & $\begin{array}{l}0.119 \\
0.027 \\
0.019\end{array}$ \\
\hline Sexual partners & $\begin{array}{l}1 \\
2+ \\
\text { None }\end{array}$ & $\begin{array}{r}36(14.9) \\
6(31.6) \\
13(16.2)\end{array}$ & $\begin{array}{r}206(85.1) \\
13(68.4) \\
67(83.8)\end{array}$ & $\begin{array}{l}1 \\
2.64(0.94-7.40) \\
1.11(0.56-2.22)\end{array}$ & $\begin{array}{l}0.065 \\
0.767\end{array}$ & $\begin{array}{l}1 \\
2.37(0.74-7.65) \\
1.09(0.53-2.26)\end{array}$ & $\begin{array}{l}0.149 \\
0.806\end{array}$ \\
\hline Feel at risk & $\begin{array}{l}\text { No } \\
\text { Yes }\end{array}$ & $\begin{array}{c}6(9.4) \\
49(17.7)\end{array}$ & $\begin{array}{r}58(90.6) \\
228(82.3)\end{array}$ & $\begin{array}{l}1 \\
2.08(0.85-5.09)\end{array}$ & 0.110 & & \\
\hline
\end{tabular}

$\mathrm{OR}$, odds ratio, $\mathrm{CI}$, confidence interval, n, number.*probability value. 
25 years of age, $57.5 \%$ were married, $53.1 \%$ had attained no or primary education, and $66 \%$ were unemployed (without formal employment either in the public or private sector). Knowledge of HIV was high with 99\% having heard about HIV/AIDS and knowing that it was sexually transmitted. HIV prevalence was higher among the indigenous Batooro tribe (17.8\%) compared to other tribes (8.3\%) $(\mathrm{P}<0.05)$. The overall HIV prevalence among those who accepted to be tested in the population serological survey (341) was 16.1\% [ $95 \%$; CI 12.5-20.6] with women having lower prevalence $(14.5 \%)$ compared to men $(18.7 \%)\left(\chi^{2}=\right.$ $0.76, \mathrm{P}=0.38$ ) (Table 1). In the univariable analysis, the Batooro were 2.4-fold [95\% CI; 0.89-6.41] more likely to be infected with HIV than other tribes in the municipality. Men were 1.4 -fold [ $95 \% \mathrm{CI}$; 0.76-2.42] more likely to be infected than women (Table 1). Having more than 2 partners increased the odds of HIV by approximately 3 -fold compared to having only one partner $(95 \% \mathrm{CI}$; $0.94-7.40, \mathrm{P}=0.065)$

In the multivariable logistic regression model (Table 1), a low level of education and age over 35 years were significantly associated with HIV prevalence $(\mathrm{P}<0.05)$. Residents with no education were twice more likely to be HIV positive than those with primary education and 4 times more than those with secondary or higher education. Most participants attributed the high HIV/AIDS prevalence in the municipality to promiscuity/multiple sexual partners (32.5\%). This was followed by prostitution (13.6\%), alcoholism (10.1\%), carelessness $(10.1 \%)$, poverty $(9.7 \%)$, ignorance $(9.5 \%)$, rape $(4.7 \%)$, drug abuse $(3.6 \%)$ and others (malice/malevolence, laziness, etc.) (6.2\%) (Figure 1).

\section{Prevention of mother to child HIV transmission and VCT records review}

Retrospective review of ANC/PMTCT data showed that 1205 clients were tested under the PMTCT program in the period July 2007 to June 2008 of which 1,141 (94.7\%) were females and 64 (5.3\%) were males, average age 23.9 years versus 30 years, respectively. Overall, 163 (13.5\%) were found to be HIV positive of which 153 were females (94.5\%) and 10 were males (5.5\%). Like in the general population, HIV prevalence was higher among men 15.6\% (95\%
CI; 7.8-26.9) compared to women 13.4\% [95\% CI; 11.5-15.6] though the difference was not significant (Table 2). Review of VCT data showed that 1971 clients were tested under the VCT program in the period July 2007 to June 2008 of which 1282 (65\%) were females and 689 (35\%) were males, mean age 26 and 28 years, respectively. The overall HIV prevalence among VCT clients was 19.4\% [95\% CI; 17.721.3] and HIV prevalence among females was 21.9\% [95\% CI; 19.7-24.3], significantly higher than that among men (14.8\%) [95\% CI; 12.3 17.7] $(\mathrm{P}<0.05)$ (Table 2$)$.

Whereas highest HIV prevalence was observed in the 35-39 age group in the population survey (30.8\%), it was highest in the $40-49$ age group in VCT (29.5\%) and the 20-24 age group in PMTCT (15.4\%). Overall, HIV prevalence among women aged 15-45 years was significantly higher in VCT (21.9\%) [95\% CI; 19.7-24.3] than in the general population (14.5\%) (95\% CI 10.0-19.7) and PMTCT (13.4\%) (95\% CI 11.5-15.6) $(\mathrm{P}<0.05)$. However, HIV prevalence among women in the general population was not significantly different from that of women of similar age in the ANC/PMTCT program (Table 2).

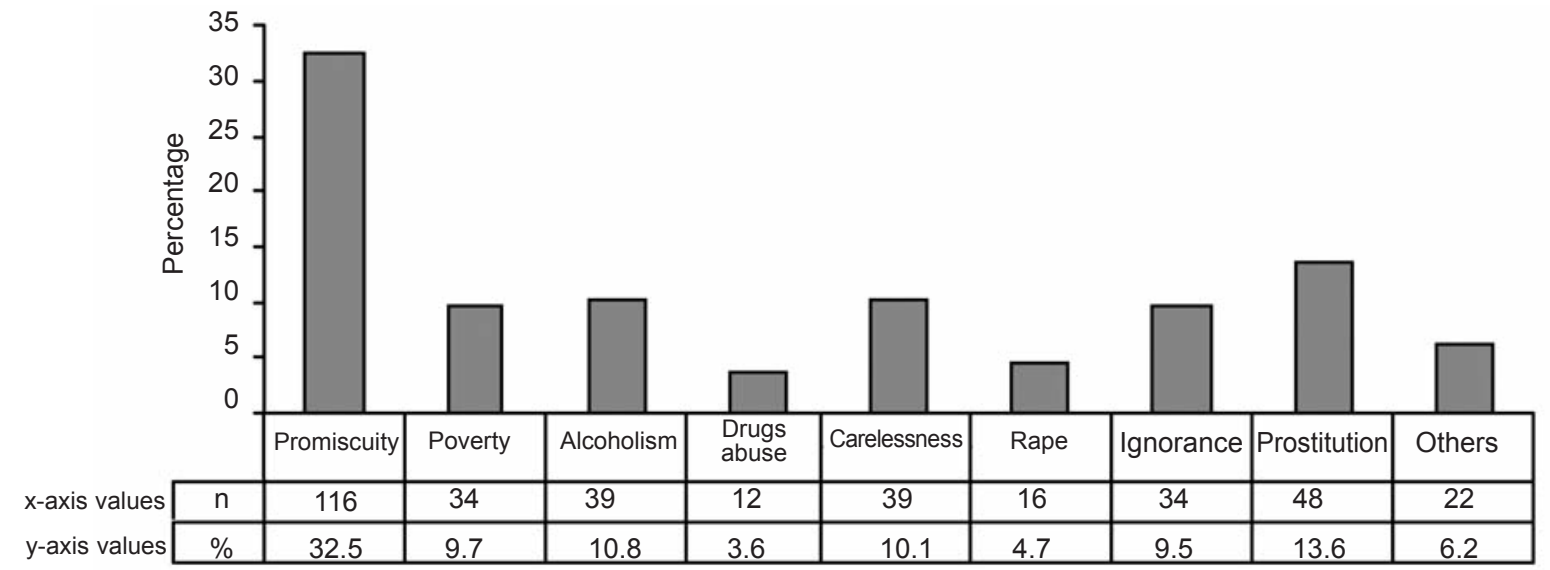

Figure 1

Perceived reasons for high HIV prevalence in Fort-Portal municipality $(\mathrm{n}=360)$. n, number of respondents who said "yes" per category.

Table 2. Comparative analysis of HIV prevalence among women in the general population, prevention of mother to child HIV transmission and voluntary counseling and testing centers by age group in Fort-Portal municipality.

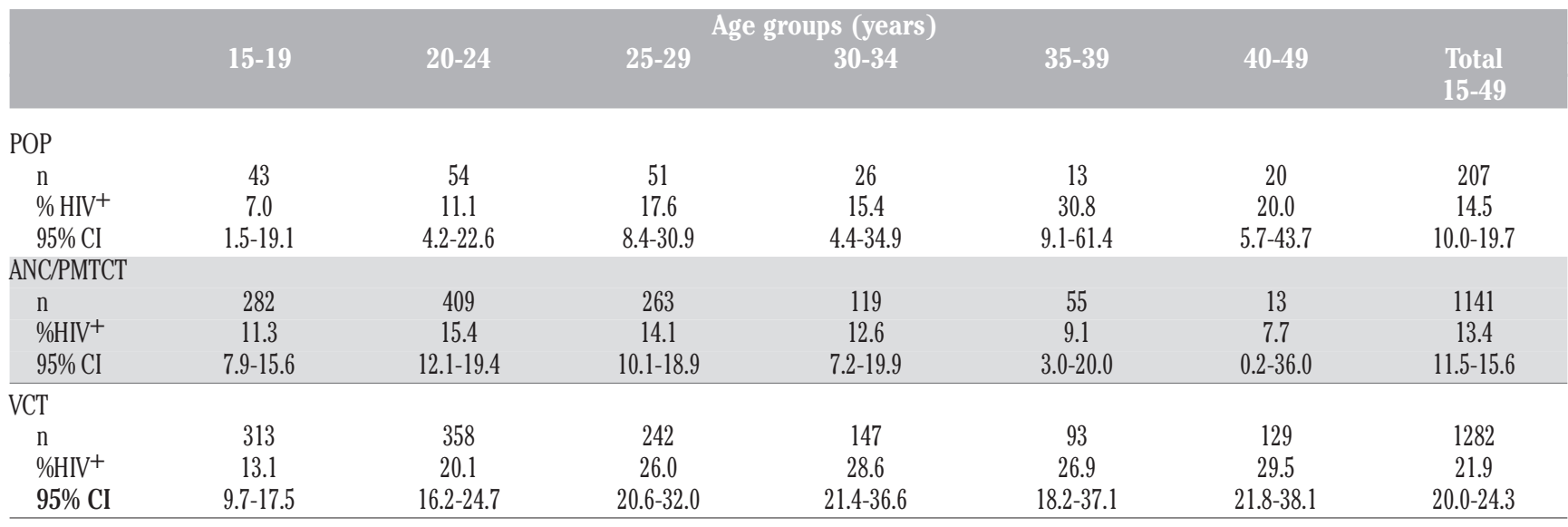

$\mathrm{Cl}$, confidence interval. 


\section{Discussion}

Though there was a slight decline in HIV prevalence compared to that previously reported, ${ }^{22,30,32,33}$ the results from this study confirm that HIV prevalence is still high in this community. This is also consistent with findings in the National sero behavioral survey of 2004/5 in which the Batooro tribe had the highest HIV prevalence (14.8\%) compared to other ethnicities in Uganda. ${ }^{10}$

The current study also shows that in this community, age over 35 years increased the odds of HIV infection by more than 3 -fold. This is consistent with a recent study in Eastern Uganda which showed that HIV incidence significantly increased in older age groups ( $>40$ years) compared to younger age groups for the period 1989-2005.12 Similar findings were also reported in Zimbabwe ${ }^{21}$ and South Africa, ${ }^{36}$ and were attributed to an increased focus on prevention among young people. We also observed that no education or little education is associated with high HIV prevalence in this community. This is consistent with other studies carried out in the region. ${ }^{67}$ Knowledge of HIV was high in this community at $99.4 \%$, which is consistent with findings in the national HIV sero and behavioral survey 2004/5 which showed that $99 \%$ of Ugandans aged 15-49 were knowledgeable about HIV transmission and prevention. ${ }^{10}$ However, the high HIV prevalence despite the high level of awareness and knowledge of HIV prevalence was paradoxical. A multi-ethnic study conducted in Western Uganda in $1995^{37}$ showed Batooro ethnic communities were at a higher risk of acquiring HIV/AIDS compared to other ethnic communities in the Rwenzori region. However, the reasons for this were not given. In this study, the perceived factors for high prevalence in this community were mainly behavioral (promiscuity/multiple sexual partners, prostitution) and socio-cultural (alcoholism, carelessness/laziness, malice/malevolence, poverty, ignorance and drug abuse) factors. Related factors have also been reported elsewhere in different subpopulations in Africa ${ }^{38-43}$ For instance, a population-based study in urban Arusha, Tanzania ${ }^{38}$ found the common risk factors for HIV transmission to be under-age marriage/cohabiting, alcoholism, multiple sexual partners, unprotected casual sex and sexually transmitted infections (STIs). Another study in Northern Tanzania ${ }^{39}$ found that alcohol consumption was a strong predictor of HIV infection. In the current study, some participants attributed the high HIV prevalence on complacency due to availability of antiretroviral drugs. Recent study findings from Eastern Uganda $^{44}$ showed that persons receiving ARVs had significantly less risk of transmitting HIV due to the strong reduction of the viral load by ARVs. However, more research is required to establish whether such attitudes towards antiretroviral therapy have any significant impact on HIV transmission.

This study also showed a high willingness to test for HIV and to be informed about HIV status (94.7\%). In 2002, the Ministry of Health in Uganda developed the first VCT policy as a means for effective HIV/AIDS management in Uganda. However, the 2004/5 National HIV sero and behavioral survey showed that only $13 \%$ of adult women and $11 \%$ of adult men in Uganda had ever taken an HIV test and received their results ${ }^{10}$ in spite of the availability of testing services. This led to the revision of the VCT policy in 2005 to include homebased HIV counseling and testing (HBHCT) and Routine Counseling and Testing (RCT) which are provider initiated HIV testing and counseling services. However, the 2006 Uganda Demographic and Health Survey (UDHS) still showed only 18\% among women and $13 \%$ among men had ever taken an HIV test and had their results. ${ }^{11}$ Previous studies in Uganda reported various barriers to HIV testing including self-stigmatization, social discrimination, and domestic violence, among others. $^{45-46}$ Our findings provide further evidence that provider initiated HIV counseling and testing could be more effective than client initiated HIV counseling and testing.

Analysis of PMTCT data showed 5.3\% male attendance which was still very low despite an intensified campaign for testing couples under the PMTCT program in Uganda. ${ }^{27}$ Factors contributing to this low involvement of male partners need to be investigated further. A comparison of the population-based HIV prevalence with PMTCT HIV prevalence showed that ANC/PMTCT HIV surveillance over-estimates HIV prevalence at younger ages (11.3\% vs. $7 \%$, respectively among 15-19 years old) and underestimates HIV prevalence at older ages (9.1\% vs. $30.8 \%$, respectively, among 35 - 39 years old). The same age pattern differences have been reported previously and were attributed to poor representation and self-selection of ANC/PMTCT clients. ${ }^{47-49}$

Although anonymous ANC HIV sero-surveillance has been previously used to monitor HIV sero-prevalence in the general population, ${ }^{50-53}$ integrated ANC/PMTCT re-enforces selection bias as some mothers are likely to stay away for fear of being tested for HIV, thus making ANC/PMTCT data unsuitable for monitoring HIV prevalence in the general population. Previous studies have established that those refusing to test are often at a higher risk of HIV infection than those who consent. ${ }^{47-49}$

In this study, it was observed that the population HIV sero-prevalence in women was significantly lower than that of women who attended VCT clinics. This is consistent with a previous study in Uganda $^{29}$ which compared prevalence trends among VCT clients and
ANC/PMTCT attendees, and showed that HIV prevalence was relatively higher in VCT clients though the overall trend was almost similar. It was also observed that HIV prevalence was higher among women (21.9\%) compared to men (14.8\%) under the VCT program and yet the reverse was observed in the populationbased survey where HIV prevalence was higher in men (18.7\%) compared to women (14.5\%). This could probably be attributed to the self-selection bias as previously reported in other studies that women who considered themselves at high risk for HIV infection were more likely to seek VCT services than those who considered themselves to be at low risk. ${ }^{27,29,53}$ Other studies have also shown that VCT services are likely to attract high-risk individuals, especially when they are linked with provision of anti-retroviral drugs. ${ }^{27,29}$

\section{Limitations}

This study, like any other, faced a number of limitations which included the likelihood that within this area, where both PMTCT and VCT services were offered, many people might have been aware of their HIV status and this may have influenced their decision to participate in the population-based sero-survey. Although our response rate was quite good, we cannot rule out the possibility of participation biases. For instance, due to uncertainty about the willingness of the community to test for HIV, the study may have suffered a selection bias by studying only those willing to test, which may have over-represented certain categories of persons in the households. Similarly, the study may have had response biases during the collection of perceived risk factors, though this concern is common to most studies of selfreported behavior. Due to the small numbers in certain age and ethnic categories during the population based-sero survey and household interviews, our estimate of HIV prevalence within these age and ethnic categories might not be precise and might, therefore, have limited generalizability. The PMTCT and VCT routine data analyzed were collected for treatment and patient care and not for research purposes, which may have over-estimated or under-estimated HIV prevalence at these centers. Finally, due to the inherent weakness of the cross-sectional study design, we could not establish causal relationships between HIV infection and perceived risk factors.

\section{Conclusions}

Although there was a slight decline compared to previous reports, the results from this study confirm that HIV prevalence was still high in this community. The factors associated with HIV infection in this community were 
being male, age over 35 years, and having no or primary education. The major perceived risk factors for high HIV prevalence by this community were promiscuity/multiple sexual partners, prostitution, alcoholism, carelessness/ laziness, malice/malevolence, poverty, ignorance and drug abuse, but their association with HIV infection needs further investigation. In order to prevent new infections, all the factors mentioned above need to be addressed and we recommend that education aimed at changing individual behavior be intensified in this community.

\section{References}

1. UNAIDS/WHO. AIDS epidemic up-date 2007. Geneva.

2. Staine J G. AIDS up date 2007: An annual overview of acquired immune deficiency syndrome. McGraw-Hill Co., Inc. 2008; New York.

3. Fylkesnes K, Musonda RM, Sichone M, et al. Declining HIV prevalence and risk behaviours in Zambia: evidence from surveillance and population-based surveys. AIDS 2001;15:907-16.

4. Mbulaiteye SM, Mahe C, Whitworth JAG, et al. Declining HIV incidence and associated prevalence over 10 years in a rural population in south-west Uganda: A cohort study. Lancet 2002;360:41-5.

5. Asamoah-Odei E, Garcia Calleja JM, Boerma JT. HIV prevalence and trends in sub-Saharan Africa: no decline and large sub regional differences. Lancet 2004;364:35-40.

6. Michelo C, Sandoy IF, Fylkesnes K. Marked HIV prevalence declines in higher educated young people: evidence from population-based surveys (1995-2003) in Zambia. AIDS 2006;20:1031-8.

7. Cheluget B, Baltazar G, Oreqe P, et al. Evidence for population level declines in adult HIV prevalence in Kenya. Sex Transm Infect 82 2006;i21-i26.

8. Yahya-Malima KI, Olsen BE, Matee MI, et al. The silent HIV epidemic among pregnant women within rural Northern Tanzania. BMC Public Health 2006;6:109.

9. UNAIDS/WHO. AIDS epidemic up-date 2006. Geneva, WHO.

10. Ministry of Health Uganda and ORC Macro. Uganda HIV/AIDS Sero-behavioural Survey 2004/2005. Kampala and Calverton 2006, Ministry of Health and ORC Macro.

11. Uganda Bureau of Statistics (UBOS) and Macro International Inc. Uganda Demographic and Health Survey. Calverton Maryland, USA 2007;UBOS and Macro International Inc.

12. Shafer LA, Biraro S, Kamali A, et al. HIV prevalence and incidence are no longer falling in Uganda - a case for renewed prevention efforts: evidence from a rural population cohort 1989-2005, and from ANC surveillance. Abstract C10. XVI International AIDS Conference 2006. 1318 August. Toronto

13. Okware S, Opio A, Musinguzi J, et al. Fighting HIV/AIDS: Is success possible? Bull World Health Organ 2001;79:1113-20.

14. Kirungi WL, Musinguzi J, Madraa E, et al. Trends in antenatal HIV prevalence in Urban Uganda associated with uptake of preventive sexual behaviour. Sex Trans Infect 2006;82:36-41.

15. Konde-Lule JK. The declining HIV sero prevalence in Uganda: what evidence? Health Trans Rev 1995;5:27-33.

16. Kamali A, Carpenter LM, Whitworth JAG, et al. Seven year trends in HIV infection rates and changes in sexual behaviour among adults in rural Uganda. AIDS 2000;14:427-34.

17. Wawer MJ, Serwadda D, Gray RH, et al. Trends in HIV-1 prevalence may not reflect trends in incidence in mature epidemics: data from the Rakai population-based cohort, Uganda. AIDS 1997;11:1023-30.

18. Stoneburner RL and Low-Beer D. Population-level HIV declines and behavioural risk avoidance in Uganda. Science 2004;304:714-8.

19. Whitworth J, Mahe C, Mbulaiteye SM, et al. HIV epidemic trend in rural south -west Uganda over a 10 year period. Trop Med \& Int. Health 2002;7:1047-52.

20. Asimmwe-Okiror G, Opio A, Musinguzi J, et al. Change in sexual behaviour and decline in HIV infection among young pregnant women in urban Uganda. AIDS 1997;11:1757-63.

21. Hallett TB, Aberle-Grasse J, Bello G, et al. Declines in HIV prevalence can be associated with changing sexual behaviour in Uganda, Urban Kenya, Zimbabwe and Urban Haiti. Sex Transm Infect 2006;82:i1i8.

22. Kilian AHD. HIV/AIDS control in Kabarole District, Uganda GTZ 2002.

23. Ministry of Health, STDs/AIDS control programme. HIV/AIDS surveillance report 2003. Kampala, Uganda, Ministry of Health.

24. Chin J. Public health surveillance of AIDS and HIV infections. Bull World Health Organ 1990;68:529-36.

25. Ghys PD, Kufa E, George MV. Measuring trends in prevalence and incidence of HIV infection in countries with generalized epidemics. Sex Transm Infect 2006;82:i52i56.

26. Garcia-Calleja JM, Gouws E, Ghys PD. National population based HIV prevalence surveys in sub-Saharan Africa: Results and
Implications for HIV and AIDS estimates. Sex Transm Infect 2006;82:iii64-iii70.

27. Hladik W, Masupu K, Roels T, et al. Prevention of mother to child transmission and voluntary counseling and testing programme data. What is their utility for HIV surveillance? AIDS 2005;19:519-24.

28. Behrendt C, Kendig N, Dambita C, et al. Voluntary testing for human immunodeficiency virus (HIV) in a prison population with a high prevalence of HIV. Am J Epidemiol 1994;139:918-26.

29. Mpairwe H, Muhangi L, Namujju PB, et al. HIV risk perception and prevalence in a program for prevention of mother-to-child HIV transmission in Uganda: comparison of women who accept voluntary counseling and testing and those tested anonymously. J Acquir Immune Defic Syndr. 2005;39: 354-7.

30. Kilian AHD, Gregson S, Ndynabangi B, et al. Reduction in risk behaviour provide the most consistent explanation for declining HIV prevalence in Uganda. AIDS 1999;13: 391-8.

31. Ministry Finance, Planning and Economic development. Uganda population and housing census: Kabarole District. MOFPED, Kampala 2002.

32. Chapman LE. Prevalence of HIV Infection in western Uganda; temporal trends and public awareness. MSc Thesis, University of Alberta 2006, Edmonton, Canada.

33. Moghusu BE. HIV prevalence at static sites in Kabarole District. Study report Mountains of the Moon University, FortPortal Uganda 2007.

34. Kish and Leslie. Survey sampling. John Wiley \& Sons NY, 1965.

35. Kasiulevicious V, Sapoka V, Filipaviciute R. Sample size calculation in epidemiological studies. Gerontologija 2006;7:225-31.

36. Department of Health South Africa. National HIV and syphilis antenatal prevalence survey 2006. Pretoria, South Africa 2007.

37. Kipp W, Kabwa P, Verbeck A, et al. Prevalence and risk factors of HIV-1 infection in three parishes in western Uganda. Trop Med Parasitol 1995;46:141-6.

38. Mnyika KS, Klepp KI, Kvale G, et al. Risk factors for HIV-1 infection among women in the Arusha region of Tanzania. J Acquir Immune Defic Syndr Hum Retrovirol 1996;11:484-91.

39. Sam NE, Masenga EJ, Seage GR 3rd, et al. Human immunodeficiency virus type 1 among bar and hotel workers in northern Tanzania: the role of alcohol, sexual behaviour, and herpes simplex virus type 2. Sex Transm Dis 2006;33:163-9.

40. Malamba S, Wagner HU, Maude G, et al. Risk factors for HIV1 infection in adults in a rural Ugandan community: a case-con- 
trol study. AIDS 1994;8:253-7.

41. Mmbaga EJ, Hussain A, Leyna G, et al. Incidence of HIV-1 infection and changes in the prevalence of reproductive tract infection and sexual risk behaviours: a population based longitudinal study in rural Tanzania. AJAR 2006;5:281-7.

42. Serwadda D, Wawer MJ, Musgrave SD, et al. HIV risk factors in three geographical strata of rural Rakai District, Uganda. AIDS 1992;6:983-9.

43. Simbayi LC, Kalichman SC, Jooste S, et al. Alcohol use and sexual risks for HIV infection among men and women receiving sexually transmitted infection clinic services in Cape Town, South Africa. J Stud Alcohol 2004;65:434-42.

44. Bunnell R, Opio A, Musinguzi J, et al. Changes in sexual behaviour and risk of HIV transmission after two years of antiretroviral therapy and prevention interventions in rural Uganda. Abstract MOAC0204. XVI International AIDS
Conference. 13-18 August, Toronto 2006.

45. Maman S, Mbwambo J, Hogan NM, et al. Women barriers to HIV-1 testing and disclosure: challenges for HIV-1 voluntary counseling and testing. AIDS Care 2001;13:595-603.

46. Pool R, Nyanzi S, Whitworth JAG. Attitudes to voluntary counseling and testing for HIV among pregnant women in rural southwest Uganda. AIDS Care 2001;13:605-15.

47. Zaba B, Boerma JT, White R. Monitoring the HIV epidemic using HIV prevalence data among young women attending antenatal clinics: prospects and problems. AIDS 2000;14:1633-45.

48. Glynn JR, Buve A, Carael M, et al. Factors influencing the difference in HIV prevalence between antenatal clinic and general population in sub-Saharan Africa. AIDS 2001;15:1717-25.

49. Capenter L, Nakiyingi J, Ruberantwari A, et al. Estimates of the impact of HIV infection on fertility in a rural Ugandan population cohort. Health Trans Rev 1997;7:113-26.

50. Rice BD, Bätzing-Feigenbaum J, Hosegood $\mathrm{V}$, et al. Population and antenatal-based HIV prevalence estimates in a high contracepting female population in rural South Africa. BMC Public Health 2007;7:160.

51. Kigadye RM, Klokke A, Nicoll A, et al. Sentinel surveillance for HIV-1 among pregnant women in a developing country: 3 years, experience and comparison with a population serosurvey. AIDS 1993;7:849-55.

52. Kwesibago G, Killewo JZJ, Sandstrom A. Sentinel surveillance and cross sectional survey on HIV infection prevalence: a comparative study. East Afr Med J 1996;73:298302.

53. Fabian M, Fylkesnes K, Nattabi B, et al. Evaluating two adjacent methods to extrapolate HIV prevalence from pregnant women to the general female population in sub-sahara Africa. AIDS 2003;17:399-405. 